\title{
Intramolecular Benzoin Reaction Catalyzed by Benzaldehyde Lyase from Pseudomonas Fluorescens Biovar I
}

\author{
Karel Hernández, Teodor Parella, Giovanna Petrillo, Isabel Usón, Claudia M. Wandtke, Jesús Joglar, \\ Jordi Bujons and Pere Clapés*
}

Dedication ((optional))

\begin{abstract}
Intramolecular benzoin reactions catalyzed by benzaldehyde lyase from Pseudomonas fluorescens biovar I (BAL) are reported. The structure of the substrates envisaged for this reaction consists of two benzaldehyde derivatives linked via an alkyl chain. The structural requirements needed to achieve the intramolecular carbon-carbon bond reaction catalyzed by BAL were established. Thus, a linker consisting of a linear alkyl chain of three carbon atoms connected through ether-type bonds to the 2 and 2' positions of two benzaldehyde moieties, which could be substituted with $\mathrm{Cl}, \mathrm{Br}$ or $\mathrm{OCH}_{3}$ at the 3 and 3' or at the 5 and 5' positions, were suitable substrates for BAL. Reactions with $61 \%-84 \%$ isolated yields on the intramolecular product, with ee values between $64 \%$ and $98 \%$, were achieved.
\end{abstract}

Intramolecular stereoselective carboligation is a challenging reaction in synthetic organic chemistry, which is essential to gain access to naturally occurring compounds and analogues. ${ }^{[1]}$ Different strategies have been developed to form intramolecular $\mathrm{C}-\mathrm{C}$ bonds. Among them are aldol reactions such as Robinson annulation ${ }^{[2]}$, Hajos-Parrish-Eder-Sauer-Wiechert reaction ${ }^{[3]}$, metal-catalyzed annulation including ring closing metathesis, ${ }^{[4]}$ and enantioselective intramolecular benzoin reactions using $N$ heterocyclic carbenes as catalysts. ${ }^{[5]}$ In addition to chemical methods, a plethora of intramolecular $\mathrm{C}-\mathrm{C}$ bond forming reactions occur in different complex metabolic pathways of living organism, catalyzed by highly evolved enzymes, such as: myoinositol 1-phosphate synthase ${ }^{[6]}$ in the inositol metabolism; 3dehydroquinate synthase $\mathrm{e}^{[7]}$ in the shikimate pathway; tetracenomycin F2 cyclase $^{[8]}$ in polyketide synthesis; taxadiene synthase $^{[9]}$ in the cyclization of geranylgeranyl diphosphate to taxa-4(5),11(12)-diene, and those involved in terpenoid metabolism. ${ }^{[10]}$ These enzymatic reactions are highly efficient and selective and they have always amazed organic chemists. In this line of thinking and to the best of our knowledge, the use of aldolases or thiamine-diphosphate (ThDP)-dependent enzymes as catalysts for asymmetric intramolecular carboligation reactions with synthetic substrates has not yet been reported. Therefore, we regarded the study of the potential

[a] Dr. K., Hernández, Dr J. Joglar, Dr. J. Bujons, Prof. Dr. P. Clapés. Catalonia Institute for Advanced Chemistry, Dept. Chemical Biology \& Molecular Modelling, IQAC-CSIC, Jordi Girona 18-26, 08034 Barcelona, Spain. E-mail: pere.clapes@iqac.csic.es

[b] Dr. T. Parella. Servei de Ressonáncia Magnética Nuclear. Departament de Química. Universitat Autònoma de Barcelona, Bellaterra (Spain).

[c] G. Petrillo. Dept. Chemical Biology \& Molecular Modelling, Instituto de Química Avanzada de Cataluña, IQAC-CSIC and Instituto de Biología Molecular de Barcelona, IBMB-CSIC (Spain). of the ThDP-dependent benzaldehyde lyase from Pseudomonas fluorescens biovar I (BAL) to catalyze the formation of intramolecular $\mathrm{C}-\mathrm{C}$ bonds via the benzoin reaction to be novel and possibly seminal for further investigations. Specifically, we studied the BAL-catalyzed intramolecular benzoin reaction between aromatic and heteroaromatic derivatives, connected via a spacer chain with ether bonds (Figure 1). These substrates should lead to cyclophane-type molecules of interest in supramolecular chemistry and would thereby open up new asymmetric synthetic routes for their preparation. ${ }^{[11]}$ Two goals were pursued: first, to gather information on the structural requirements for these compounds to identify suitable substrates for the intramolecular reaction catalyzed by BAL; and second, to study the scope and limitations of these enzymatic reactions. To this end, the length of the alkyl linker chain, the functional groups in the linker and the substitutions in the aromatic rings were systematically investigated.

Initially, the position of the linker in the aromatic ring and the number of methylene units in the alkyl chain connecting the two benzaldehyde units were studied (compounds 1-3, Figure 1). Ether linkages were established between the alkyl chain and the aromatic moiety. The synthesis of 1-3 was accomplished by the reaction between the corresponding hydroxybenzaldehyde and 1,n-dibromoalkane under basic conditions, with 31\%-97\% isolated yields (see Supporting Information).
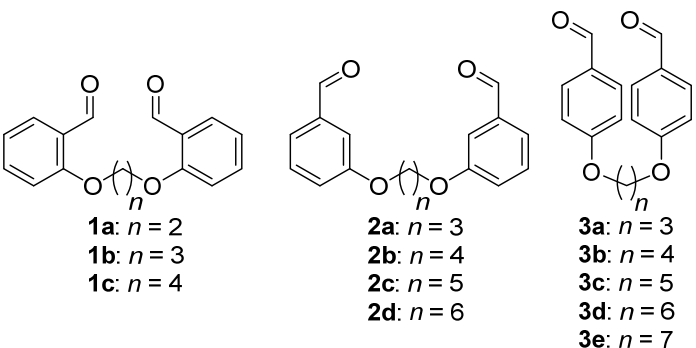

Figure 1. The 2,2'-, 3,3'- and 4,4'-linked dibenzaldehyde derivatives proposed as substrates for a BAL-catalyzed intramolecular benzoin reaction.

The substrate with symmetric 2,2'-anchoring of the linker chain with three methylenes, $\mathbf{1 b}$ (Scheme 1A), gave the intramolecular

[d] Prof. I. Usón. Instituto de Biología Molecular de Barcelona, IBMBCSIC, Institució Catalana de Recerca i Estudis Avançats (ICREA)

[e] C. M. Wandtke. Institut für Anorganische Chemie, Universität Göttingen, Göttingen (Germany).

Supporting Information for this paper is available via a link at the end of the document. 
product $(R)-4$ with $77 \%$ isolated yield and no intermolecular benzoin product being detected. Chiral HPLC analysis indicated that the reaction was highly enantioselective $(90 \%$ ee of the $R$ configured product). However, neither of the other two 2,2'anchored analogues with shorter or longer alkyl linker chains (i.e., 1a and 1c) afforded any detectable amount of benzoin products. A molecular model of $\mathbf{1 b}$ bound to the ThDP cofactor of BAL (Figure 2) indicates that the pre-reaction complex before cyclization is tightly packed in the narrow active site. This suggests that the substrate selectivity of the intramolecular benzoin reaction is mostly related to the steric limitations of the cavity. ${ }^{[12]}$

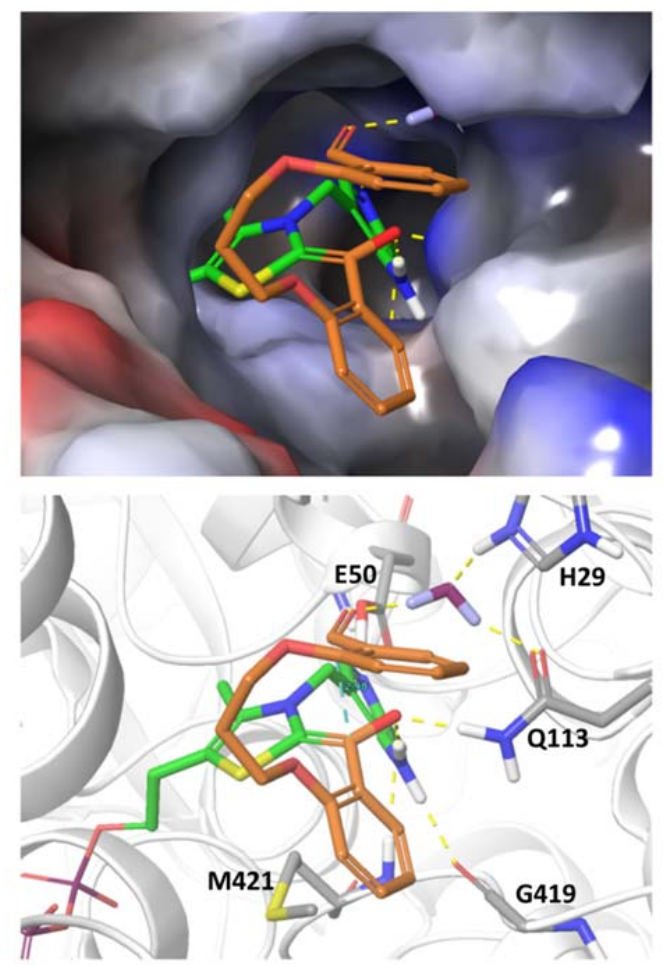

Figure 2. Molecular model of $\mathbf{1 b}$ (orange) covalently bound to the ThDP cofactor (green) in the active center of BAL (PDB 3D7K). ${ }^{[13]}$ The model corresponds to the QM/MM minimized (B3LYP/6-31G ${ }^{* *}$ ) enamine intermediate (III in Figure S46) prior to the cyclization step (distance between reactive Catoms: $2.98 \AA$ ).

The 3,3'-linked benzaldehyde derivatives with $n=3,4$ (2a-b) furnished only the intermolecular products $\mathbf{5 a}$ and $\mathbf{5 b}$, with conversions of around $82 \%$ and isolated yields of $40 \%$ and $53 \%$, respectively (Scheme 1B). Increasing the concentration of BAL (>2.5 $\mathrm{U} \mathrm{mL} \mathrm{m}^{-1}$, one $\mathrm{U}$ of activity was defined as the amount of BAL which catalyzed the formation of $1 \mu \mathrm{mol}$ of benzoin per minute at $25{ }^{\circ} \mathrm{C}$ and $\mathrm{pH} 8.0$.) or the incubation time $(>24 \mathrm{~h})$ resulted in the disappearance of both substrate and product signals in the HPLC, probably due to polymerization reactions (Figure S47A). On the other hand, no product was detected using 2c-d and 3a-e under any of the conditions tested.

The influence of the concentration of $\mathbf{1 b}$ and BAL on the yield of the intramolecular reaction was therefore studied (see Supporting Information). At concentrations of [1b] $>20 \mathrm{mM}$, a sharp decrease in conversion was observed. A number of reasons could be proposed to explain this, among them, protein crosslinking, inactivation at the solid-liquid interphase, or substrate/product inactivation. (Figure S1). The intramolecular product yield increased with the BAL concentration up to $82 \%$ at $160 \cup \mathrm{mL}^{-1}$ (Figure 2S).

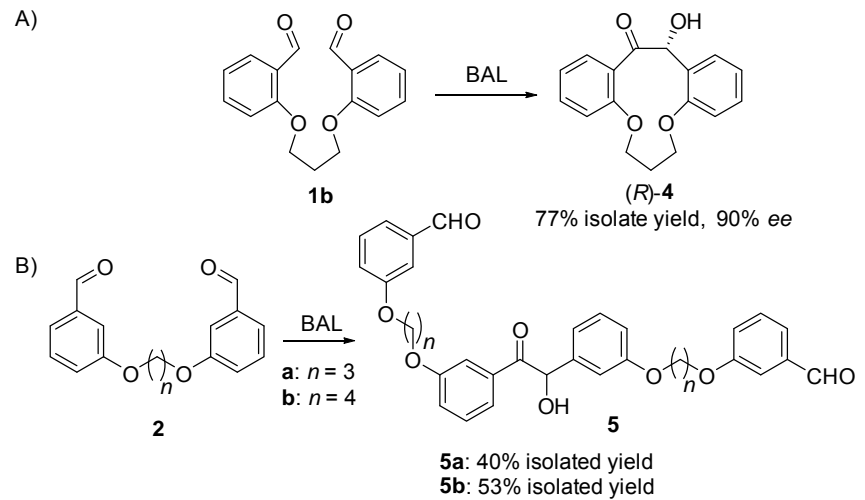

Scheme 1. BAL-catalyzed intramolecular (A) and intermolecular benzoin reactions $(B)$ of $\mathbf{1 b}$ and $\mathbf{2 a - b}$, respectively. Conditions: reaction volume $1 \mathrm{~mL}$ [1b, 2a-b] = $10 \mathrm{mM}$, carbonate buffer $(50 \mathrm{mM}, \mathrm{pH}=8)$ containing $\mathrm{MgSO}_{4}(2.5$ $\mathrm{mM})$ and ThDP $(0.15 \mathrm{mM})$, DMSO $(20 \% \mathrm{v} / \mathrm{v})$, BAL $(80 \mathrm{U}$ and $2.5 \mathrm{U}$ for the reactions depicted in $\mathrm{A}$ and $\mathrm{B}$, respectively), $\mathrm{T}=25^{\circ} \mathrm{C}$.

The alternative synthetic strategy of obtaining the benzoin derivative $\mathbf{6}$, from 2-hydroxybenzaldehyde by BAL catalysis, and subsequent reaction with 1,3-dibromopropane, yielded racemic rac-4 (Scheme 2). Non-enzymatic partial racemization of 6 was already observed under the reaction conditions of BAL catalysis (i.e., 50\% ee by chiral HPLC, Figure S54). The racemization was strongly favored by the 2-substituted hydroxyl derivative, via a mechanism of $\alpha$-ketol-type rearrangement of benzoin derivatives under basic conditions. ${ }^{[14]}$ Therefore, it was only possible to obtain the enantiopure product through the biocatalytic intramolecular benzoin reaction.

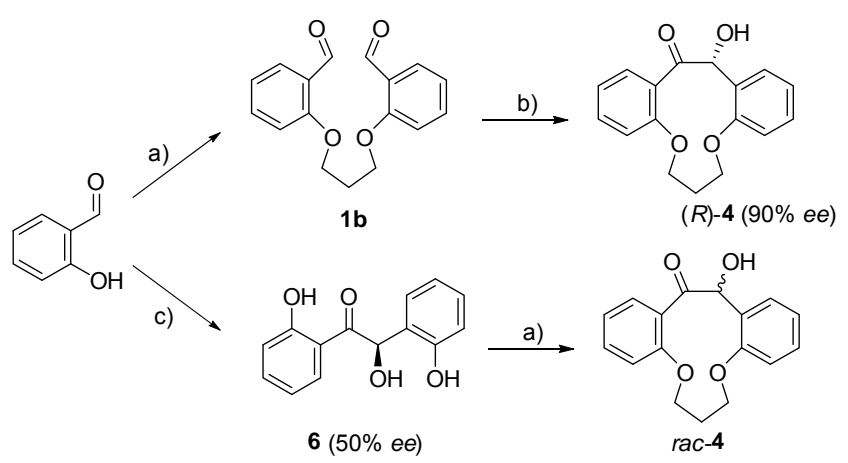

Scheme 2. Chemo-enzymatic synthesis of (R)-4 and rac-4. a) 1,3dibromopropane, $\mathrm{K}_{2} \mathrm{CO}_{3}, \mathrm{CH}_{3} \mathrm{CN}$, reflux $12 \mathrm{~h}$; b) [1b] $=20 \mathrm{mM}, 50 \mathrm{mM}$ carbonate buffer $\mathrm{pH}=8$, containing $\mathrm{MgSO}_{4}(2.5 \mathrm{mM})$ and ThDP $(0.15 \mathrm{mM})$, DMSO (20\% v/v), BAL (80 U), T = $25^{\circ} \mathrm{C}, 24 \mathrm{~h}$; c) 2-hydroxybenzaldehyde (0.5 $\mathrm{M}), 50 \mathrm{mM}$ carbonate buffer $\mathrm{pH}=8$, containing $\mathrm{MgSO}_{4}(2.5 \mathrm{mM}), \operatorname{ThDP}(0.15$ $\mathrm{mM})$ and DMSO $(20 \% \mathrm{v} / \mathrm{v}), \mathrm{BAL}(40 \mathrm{U}), \mathrm{T}=25^{\circ} \mathrm{C}, 24 \mathrm{~h}$. 
We next examined the effect of modifications in both aromatic rings (7, 9-12), aldehyde groups (8) and in the linker chain (1315) (Figure 3). The substrates were designed based on the initial optimized 2,2' position of the linker with three methylene units ( $n$ $=3$ ).

The methoxy- and chloro-substituted benzaldehydes 7a-d $\left(X=X^{\prime}\right.$ $=\mathrm{OMe}, \mathrm{Y}=\mathrm{C})$ and $7 \mathrm{e}\left(3 \mathrm{X}=3 \mathrm{X}^{\prime}=\mathrm{Cl} ; \mathrm{Y}=\mathrm{C}\right)$ (Figure 3) were synthetized according to the methodology described for 1-3 with $63 \%-88 \%$ isolated yields. The halogen-substituted $7 \mathrm{f}-\mathrm{j}$ and the rest 8-15 required different starting materials and reaction conditions (see detailed description in the Supporting information).

The symmetric substrates, $7 \mathbf{a}, 7 \mathrm{c}$ and $7 \mathrm{e}$, with substituents at $3,3^{\prime}$ or $5,5^{\prime}$ positions of the aromatic rings, furnished the corresponding intramolecular products: 16a, 16c and 16e, respectively (Table 1 ). On the other hand, no reaction was detected with $\mathbf{7 b}$ and $\mathbf{7 d}$, bearing methoxy substituents at $4,4^{\prime}$ and 6,6 ' positions, nor with $\mathbf{7 f}$ and $\mathbf{7 g}$, with halogen substituents at $5,5^{\prime}$ positions. The asymmetric halogen monosubstituted compounds at 5 or $5^{\prime}$ position $\mathbf{7 h} \mathbf{- i}$, and $7 \mathbf{j}$ bearing a pyridine moiety, were substrates, which furnished mixtures of regioisomers 16 and $\mathbf{1 7}$. For $\mathbf{7 j}$, BAL had a clear preference for the pyridine moiety as acceptor $(67 \% \mathbf{1 7 j})$, whereas for $\mathbf{7 h}$-i, it was nonselective (Table 1). Substrates containing phenylacetaldehyde (8), thiophene-2-carbaldehyde (9, 12), 1naphthaldehyde (10) and 2-naphthaldehyde (11) moieties were not tolerated and the starting material was recovered after $24 \mathrm{~h}$ of incubation. Furthermore, compounds with modifications in the linker, i.e. 13-15, were not substrates for BAL either.

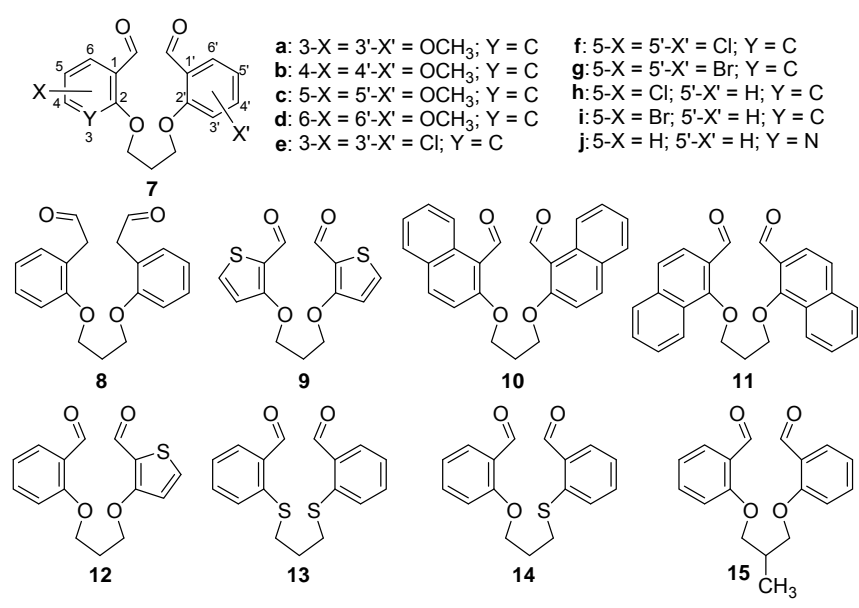

Figure 3. Dialdehydes tested for the intramolecular benzoin reaction catalyzed by BAL.

The structures of compounds 16 and 17 obtained in this way (Table 1 ) were confirmed by NMR. To unequivocally determine their absolute configurations, $\mathbf{1 6 a}$ and $\mathbf{1 6 c}$ were analyzed by single-crystal X-ray diffraction (Figure 4). ${ }^{[15]}$ For compound $16 \mathbf{e}$, two different crystal forms could be found: a majority of long and platy needles belonging to space group $\mathrm{C} 2$ and showing $R$ configuration; and a few smaller block-shaped crystals that contained a racemate. $R$-configured benzoin adducts are usually obtained by BAL-catalyzed reactions. ${ }^{[16]}$ The major stereochemical outcome was thus unbiased by the structure of these connected dibenzaldehyde substrates. ${ }^{[17]}$

Table 1. The BAL-catalyzed intramolecular benzoin reaction of dibenzaldehyde derivatives $7 .^{[a]}$

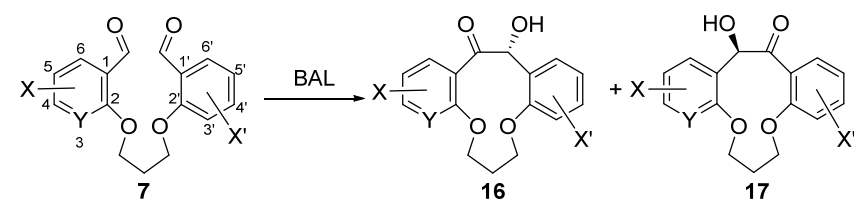

\begin{tabular}{|c|c|c|c|c|}
\hline Substrate & $\begin{array}{l}\text { Conversion } \\
(\%)^{[\mathrm{b}]}\end{array}$ & Product & $\begin{array}{l}\text { Isolated } \\
\text { Yield (\%) }\end{array}$ & $e e^{[c]}(\%)$ \\
\hline $7 a$ & 72 & $16 a$ & 67 & $98(R)$ \\
\hline $7 c$ & 89 & $16 c$ & 84 & $98(R)$ \\
\hline $7 e$ & $50,90^{[d]}$ & $16 e$ & 61 & $64(R)$ \\
\hline $7 \mathrm{~h}$ & 72 & $\begin{array}{l}\text { 16h:17h } \\
2: 3^{[\mathrm{e}][f]}\end{array}$ & $58^{[g]}$ & $-^{[\mathrm{h}]}$ \\
\hline $7 \mathbf{i}$ & $35,75^{[\mathrm{d}]}$ & $\begin{array}{l}\mathbf{1 6 i} \mathbf{i} \mathbf{1 7} \mathbf{i} \\
1: 1^{\left.1^{e}\right][f]}\end{array}$ & $65^{[\mathrm{g}]}$ & $-\left[{ }^{[h]}\right.$ \\
\hline $7 \mathbf{j}$ & 99 & $16 \mathrm{j}: 17 \mathrm{j} 3: 7^{[\mathrm{b}]}$ & $\begin{array}{l}26(\mathbf{1 6} \mathbf{j}) \\
67(\mathbf{1 7} \mathbf{j})\end{array}$ & $\begin{array}{l}90(R) \\
99(R)\end{array}$ \\
\hline
\end{tabular}

[a] [7] $=20 \mathrm{mM},[\mathrm{BAL}]=160 \mathrm{U} \mathrm{mL}^{-1}$, all other conditions as in Scheme $1 \mathrm{~A}$. [b] Determined by reverse phase HPLC. [c] Determined by chiral HPLC analysis (see Supporting Information). [d] This second figure is the conversion achieved after the repeated addition of $160 \mathrm{U} \mathrm{mL}^{-1}$ of BAL and an additional $24 \mathrm{~h}$ of reaction time. [e] Proportion 16:17 determined by NMR. [f] The regioisomeric mixtures could not be separated by normal or reverse phase HPLC. [g] Product obtained as a mixture of regioisomers. [h] Not determined.
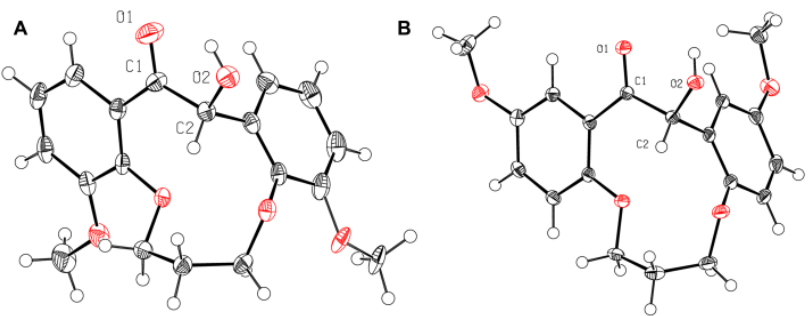

Figure 4. X-Ray structures of $(R)-16 \mathrm{a}(\mathrm{A})$ and $(R)-16 \mathrm{c}(\mathrm{B})$. ORTEP-type plot displaying one molecule with $50 \%$ probability ellipsoids. (Note CCDC-1427223, 1427224,1427225 and 1427226 contain crystallographic data and structure factors for $(R)-16 \mathbf{a},(R)-16 \mathrm{c},(R)-16 \mathrm{e}$ and rac-16e, respectively. The data can be obtained free of charge from The Cambridge Crystallographic Data Centre via www.ccdc.cam.ac.uk/data request/cif.

In summary, here we uncover the unprecedented capacity of BAL to catalyze intramolecular asymmetric benzoin reactions. This was accomplished using aromatic aldehyde derivatives connected via a linker chain. The structural requirements of the substrates for the reaction to proceed were an alkyl chain linker of three carbon atoms, bound through ether-linkages to the 2,2'position of two benzaldehyde moieties. Substituents at 3- or 5- 
position of the benzaldehyde rings, as well as pyridine analogues are also accepted by BAL.

This led to novel cyclic benzoin adducts, analogues of pinacolophanes, and intermediates in the synthesis of stilbenophanes: both compounds are of interest in supramolecular chemistry. The structural requirements established for the BAL-catalyzed intramolecular reaction may be instrumental in future developments toward the synthesis of a novel class of cyclophane-type compounds. Along these lines, further experiments to widen the substrate scope of this reaction, including new 2,3'-, 2,4'-, and 3,4'-linked benzaldehyde derivatives, and different heteroatom-substituted spacer chains are in progress.

\section{Acknowledgements}

This work was supported by the Spanish Ministry of Economy, Industry and Competitiveness (MINECO) and the European Regional Development Fund (grant CTQ2015-63563-R to P.C., CTQ2015-64436-P to T.P. and BIO2015-64216-P and MDM2014-0435 to I.U.) and by the COST action CM1303 Systems Biocatalysis. K.H. acknowledges the CSIC for a JAE predoctoral fellowship; and G.P. acknowledges the Generalitat de Catalunya and Biochemize S.L. for an Industrial Doctorate predoctoral fellowship.

Keywords: Biocatalysis • Asymmetric catalysis - C-C coupling • Benzaldehyde lyase $\cdot$ Intramolecular benzoin reaction

[1] a) Y. Usami, in Studies in Natural Products Chemistry, Vol. 41 (Ed.: R. Atta ur), Elsevier, 2014, pp. 287; b) O. Arjona, A. M. Gomez, J. C. Lopez, J. Plumet, Chem. Rev. 2007, 107, 1919; c) K. C. Nicolaou, D. J. Edmonds, P. G. Bulger, Angew. Chem. Int. Ed. 2006, 45, 7134; Angew. Chem. 2006, 118, 7292. a) R. M. Acheson, R. Robinson, J. Chem. Soc. 1952, 1127; b) G. Guillena, C. Nájera, D. J. Ramón, Tetrahedron: Asymmetry 2007. 18, 2249

a) J. E. Baldwin, M. J. Lusch, Tetrahedron 1982, 38, 2939; b) S. Mukherjee, J. W. Yang, S. Hoffmann, B. List, Chem. Rev. 2007, $107,5471$.

[4] a) T. Jin, J. Zhao, N. Asao, Y. Yamamoto, Chem. Eur. J. 2014, 20 3554; b) R. J. Felix, C. Munro-Leighton, M. R. Gagné, Acc. Chem. Res. 2014, 10.1021/ar500047j

[5] a) D. Enders, O. Niemeier, T. Balensiefer, Angew. Chem. Int. Ed. 2006, 45, 1463; Angew. Chem. 2006, 118, 1351; b) H. Takikawa, Y. Hachisu, J. W. Bode, K. Suzuki, Angew. Chem. Int. Ed. 2006 45, 3492; Angew. Chem. 2006, 118, 3572.

[6] a) F. Tian, M. E. Migaud, J. W. Frost, J. Am. Chem. Soc. 1999 121, 5795; b) F. A. Loewus, M. W. Loewus, Annu. Rev. Plant Phys. 1983, 34, 137.

[7] J. R. Knowles, Aldrichim. Acta 1989, 22, 59.

[8] a) B. Shen, C. R. Hutchinson, Biochemistry 1993, 32, 11149; b) T. B. Thompson, K. Katayama, K. Watanabe, C. R. Hutchinson, I. Rayment, J. Biol. Chem. 2004, 279, 37956.

[9] D. C. Williams, B. J. Carroll, Q. Jin, C. D. Rithner, S. R. Lenger, H G. Floss, R. M. Coates, R. M. Williams, R. Croteau, Chem. Biol. 2000, 7, 969 .

[10] a) D. E. Cane, H. Ikeda, Acc. Chem. Res. 2011, 45, 463; b) D.-K. Ro, in Plant Metabolism and Biotechnology,

10.1002/9781119991311.ch8, John Wiley \& Sons, Ltd, 2011, pp. 217; c) R. J. Cox, Annu. Rep. Prog. Chem., Sect. B: Org. Chem. 2000, 96, 231; d) M. W. Huff, D. E. Telford, Trends Pharmacol. Sci. 2005, 26, 335.

[11] a) H. R. Darabi, M. Mirzakhani, K. Aghapoor, J. Organomet. Chem. 2015, 786, 10; b) H. R. Darabi, M. H. Karouei, M. J. Tehrani, K. Aghapoor, M. Ghasemzadeh, B. Neumüller, Supramol. Chem. 2011, 23, 462.

[12] M. Knoll, M. Müller, J. Pleiss, M. Pohl, Chembiochem 2006, 7 1928.

[13] G. S. Brandt, N. Nemeria, S. Chakraborty, M. J. McLeish, A. Yep, G. L. Kenyon, G. A. Petsko, F. Jordan, D. Ringe, Biochemistry 2008, 47, 7734

[14] M. Karino, D. Kubouchi, K. Hamaoka, S. Umeyama, H. Yamataka, J. Org. Chem. 2013, 78, 7194.

[15] G. Sheldrick, Acta Crystallographica Section A 2008, 64, 112.

[16] P. P. Giovannini, O. Bortolini, A. Massi, Eur. J. Org. Chem. 2016 2016, 4441.

[17] a) A. S. Demir, Ö. Şeşenoglu, P. Dünkelmann, M. Müller, Org. Lett. 2003, 5, 2047; b) P. Ayhan, I. Simsek, B. Cifci, A. S. Demir, Org. Biomol. Chem. 2011, 9, 2602. 
Entry for the Table of Contents (Please choose one layout)

\section{COMMUNICATION}

Benzaldehyde lyase from Pseudomonas fluorescens biovar I (BAL) can catalyze enantioselective intramolecular benzoin reactions. The structural requirements for the substrate were two benzaldehyde moieties, alone or with additional 3,3'and 5,5 '- substituents, connected via ether bonds to a $\mathrm{C}_{3}$-linker at the 2,2'position. The synthesis of non-natural macrocycles is now possible by this biocatalytic route.
K. Hernández, T. Parella, G. Petrillo, I. Usón, C. M. Wandtke, J. Joglar, J. Bujons and P. Clapés*

Page No. - Page No.

Intramolecular Benzoin Reaction Catalyzed by Benzaldehyde Lyase from Pseudomonas Fluorescens Biovar I 